\title{
Component Model Effect on Fast-Front Overvoltages in Gas Insulated Substations
}

\author{
Jihong Kim* ${ }^{*}$ Levente Czumbil ${ }^{* *}$ and Hassan Nouri** \\ *Electro Electric Systems Research Institute, Hyundai Heavy Industries Co., Ltd. Dong-gu Ulsan, South Korea \\ ${ }^{* *}$ Power Systems, Electronics and Control research Laboratory at University of the West of England, Bristol, U.K.
}

\begin{abstract}
The proper modelling of transmission line towers and conductors plays an essential part in the travelling-wave analysis of fast front overvoltages due to lightning surges in overhead power lines connected to Gas Insulated Substations. This paper investigates the effect of different simulation component models on the transient overvoltages produced at the entrance of the Gas Insulted Substation. A new combined tower model that takes into consideration both the bracings and the damping effect of each tower section is proposed.
\end{abstract}

Index Terms-fast front overvoltages, tower models, lightning current models, gas insulate substation, back flashover.

\section{INTRODUCTION}

One of the principal causes of Fast Front Overvoltages (FFO) in power systems is lightning stroke to transmission lines. Lightning overvoltages have a wave head of several microseconds and are an important factor in determining the insulation design of substation equipment, especially in cases of Gas Insulated Substations (GIS) [1, 2].

Lightning overvoltages could be produced by direct lightning stokes to phase wires or by back flashover when the lightning stroke hits the tower or the ground wire and the voltage across the phase wire insulator string exceeds its withstanding capability.

A direct strike to a power line is very rare, and most of the lightning strikes the top of the transmission tower. The lightning back flashover effects are recognized as one of the major causes of transmission line (TLine) outages and may also result in substation outages, caused by incoming surges with amplitude exceeding the insulation level of the GIS equipment [2].

It is very difficult to observe the lightning overvoltage experimentally, thus a numerical simulation is adopted in order to investigate it [3]. This paper studies the effect of different simulation component implementation (e.g. tower model, footing resistance, lightning current model and waveform, etc.) on the transient overvoltages produced at the Gas Insulated Substation entrance by lightning strokes to an adjoining overhead power line.

\section{TRANSMISSION LINE TOWER MODELLING}

One of the most important steps in the evaluation of fast front overvoltages produced by lightning strikes to overhead power lines connected to GIS, is the accurate modelling of transmission line towers. Although the lightning response of a transmission line tower is an electromagnetic phenomenon, the representation of a tower is usually made in circuit terms.
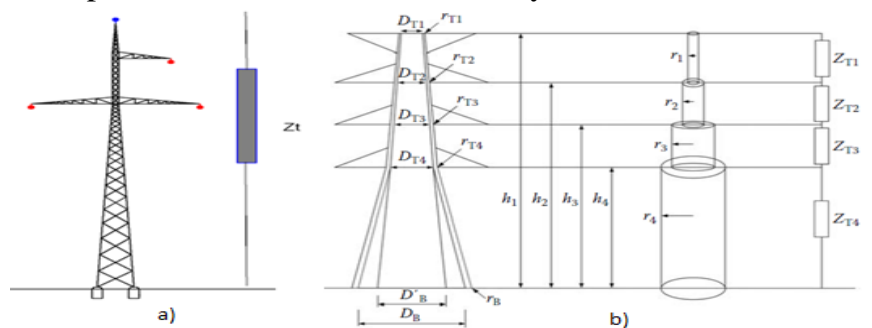

Fig. 1. a) Single lossless transmission line model;

b) Multi-Story transmission line model;

\section{A. Single lossless transmission line models}

The simplest representation of power line tower is a lossless distributed-parameter transmission line, characterized by its surge impedance and travel time. Table I shows the different tower surge impedance formulas presented in the literature, based on an electromagnetic theory approach or on experimental measurements. Due the multiple paths through crossarms and the lattice structure of the tower, the propagation velocity of the lightning current and voltage waves across the tower is reduced to $290 \cdot 10^{6} \mathrm{~m} / \mathrm{s}$.

TABLE I

DIFFERENT TOWER SURGE IMPEDANCE FORMULAS

\begin{tabular}{|c|c|}
\hline Author & Proposed Formula \\
\hline Wagner [4] & $Z_{S}=60 \cdot \ln \left(2 \sqrt{2} \cdot \frac{H}{R_{B}}\right)$ \\
\hline Sargent [4] & $Z_{S}=60 \cdot \ln \left(\sqrt{2} \cdot \frac{\sqrt{R_{B}{ }^{2}+H^{2}}}{R_{B}}\right)$ \\
\hline Jordan [4] & $Z_{S}=60 \cdot \ln \left(\frac{H}{R_{B}}\right)-60$ \\
\hline $\begin{array}{c}\text { CIGRE [2] } \\
\text { IEEE [5] }\end{array}$ & $Z_{S}=60 \cdot \ln \left(\cot \left(\frac{1}{2} \cdot \arctan \left(\frac{R_{A v g}}{H}\right)\right)\right)$ \\
\hline
\end{tabular}


TABLE I (CONTINUES)

DIFFERENT TOWER SURGE IMPEDANCE FORMULAS

\begin{tabular}{|c|c|}
\hline Author & Proposed Formula \\
\hline $\begin{array}{l}\text { Corrected } \\
\text { CIGRE [4] } \\
\text { Baba \& Ishi }\end{array}$ & $Z_{T}=\sqrt{\frac{\pi}{4}} \cdot 60 \cdot\left(\ln \left(\cot \left(\frac{1}{2} \cdot \arctan \left(\frac{R_{\text {avg }}}{H}\right)\right)\right)-\ln \sqrt{2}\right.$ \\
\hline Ametani [6] & {$\left[\begin{array}{l}\ln \frac{\left(\sqrt{R_{E q}{ }^{2}+H^{2}}+H\right)^{2}}{R_{E q} \cdot\left(\sqrt{R_{E q}{ }^{2}+4 H^{2}}+2 H\right)}+ \\
+\frac{3 R_{E q}+\sqrt{{R_{E q}}^{2}+4 H^{2}}-4 \sqrt{R_{E q}^{2}+H^{2}}}{2 H}\end{array}\right.$} \\
\hline Hara [7] & $Z_{S}=60 \cdot\left(\ln \frac{2 \sqrt{2} \cdot H}{R_{E q}}-2\right)$ \\
\hline
\end{tabular}

where: $H$ is tower height; $R_{B}, R_{A v g}$ and $R_{E q}$ are tower base, average and equivalent radius by considering the tower as system of multiple vertical parallel conductors, respectively.

Due the fact that most of the tower surge impedance equations are empirical ones or have been developed by imposing a set of simplifying conditions, in order to determine the most accurate evaluation formula the authors have developed MathCad algorithm which implement and test the above presented equations for different tower geometries. Obtained results have been compared to measured surge impedance values presented in literature [6, 8]. Table II presents the investigate tower geometries:

TABLE II.

INVESTIGATED TOWER GEOMETRIES $[6,8]$

\begin{tabular}{|c|c|c|c|c|c|c|c|}
\hline No. & $\begin{array}{c}\text { Voltage } \\
\text { Level }\end{array}$ & $\begin{array}{c}\mathbf{R}_{\mathrm{T}} \\
{[\mathbf{m}]}\end{array}$ & $\begin{array}{c}\mathbf{R}_{\mathrm{m}} \\
{[\mathbf{m}]}\end{array}$ & $\begin{array}{c}\mathbf{R}_{\mathbf{8}} \\
{[\mathbf{m}]}\end{array}$ & $\begin{array}{c}\mathbf{H}_{\mathbf{1}} \\
{[\mathbf{m}]}\end{array}$ & $\begin{array}{c}\mathbf{H}_{\mathbf{2}} \\
{[\mathbf{m}]}\end{array}$ & $\begin{array}{c}\text { Zs } \\
\text { Measured }\end{array}$ \\
\hline O1 & $1100 \mathrm{kV}$ & 2.4 & 4 & 12.5 & 51 & 88 & $138 \Omega$ \\
\hline 02 & $1000 \mathrm{kV}$ & 3 & 6.5 & 14 & 80 & 80 & $144 \Omega$ \\
\hline 03 & $1000 \mathrm{kV}$ & 2.5 & 4 & 11 & 60 & 60 & $149 \Omega$ \\
\hline 04 & $500 \mathrm{kV}$ & 1.9 & 2.2 & 5.4 & 28.7 & 32.2 & $119 \Omega$ \\
\hline 05 & $500 \mathrm{kV}$ & 1.5 & 2.3 & 5.6 & 31 & 31 & $154 \Omega$ \\
\hline 06 & $500 \mathrm{kV}$ & 1 & 1.9 & 4 & 24 & 24 & $149 \Omega$ \\
\hline 07 & $154 \mathrm{kV}$ & 0.265 & 0.535 & 1.225 & 7.42 & 7.58 & $131 \Omega$ \\
\hline
\end{tabular}

The evaluation error produced by each of the above presented tower surge impedance formula are presented in Table III. It can be observed that the most accurate results are provided by Ametani's formula. However, due the fact that the tower response to a lightning strike is directly dependent on its surge impedance value one could also use the corrected CIGRE formula in order to obtain a higher margin on the evaluated overvoltage values at GIS entrance.

TABLE III.

OBTAINED EVALUATION ERRORS

\begin{tabular}{|c|c|c|c|c|c|c|c|}
\hline \multirow{2}{*}{$\underset{\text { Formula }}{\text { Zs }}$} & \multicolumn{7}{|c|}{ Evaluation Error } \\
\hline & $\begin{array}{c}\text { Tower } \\
01\end{array}$ & $\begin{array}{c}\text { Tower } \\
02\end{array}$ & $\begin{array}{c}\text { Tower } \\
03\end{array}$ & $\begin{array}{c}\text { Tower } \\
04\end{array}$ & $\begin{array}{c}\text { Tower } \\
\text { o5 }\end{array}$ & $\begin{array}{c}\text { Tower } \\
06\end{array}$ & $\begin{array}{c}\text { Tower } \\
07\end{array}$ \\
\hline Wagner & $49.93 \%$ & $51.25 \%$ & $38.09 \%$ & $74.58 \%$ & $33.16 \%$ & $41.93 \%$ & $62.36 \%$ \\
\hline Sargent & $19.80 \%$ & $22.37 \%$ & $10.18 \%$ & $39.63 \%$ & $6.15 \%$ & $14.02 \%$ & $30.61 \%$ \\
\hline Jordan & $2.87 \%$ & $4.86 \%$ & $14.21 \%$ & $1.93 \%$ & $20.14 \%$ & $12.29 \%$ & $4.00 \%$ \\
\hline CIGRE & $33.94 \%$ & $30.47 \%$ & $25.14 \%$ & $52.33 \%$ & $18.57 \%$ & $24.22 \%$ & $44.37 \%$ \\
\hline Corr. CIGRE & $5.35 \%$ & $2.82 \%$ & $1.46 \%$ & $19.52 \%$ & $6.88 \%$ & $2.28 \%$ & $13.88 \%$ \\
\hline Ametani & $0.33 \%$ & $2.54 \%$ & $11.61 \%$ & $1.99 \%$ & $17.41 \%$ & $9.81 \%$ & $6.58 \%$ \\
\hline Hara & $1.15 \%$ & $3.20 \%$ & $12.61 \%$ & $0.08 \%$ & $18.59 \%$ & $10.69 \%$ & $5.82 \%$ \\
\hline
\end{tabular}

\section{B. Ishii Multi-Story Tower Model}

For a more realistic representation of transmission line towers Ishii proposed a multi-story tower model where, in order to take into account the attenuation of the traveling wave long tower height, each tower section is represented by a lossless TLine in series with a parallel R-L circuit (see Fig. 2).

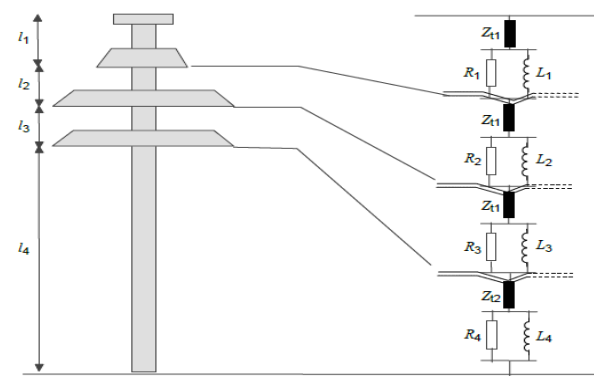

Fig. 2. Ishii Multi-Story Tower Model [4].

The values of the parameters, and the model itself, have been revised in more recent years by Ametani [9]. Thus, the damping resistances and inductances could be evaluated based on tower section surge impedance according to the following equations:

$$
\begin{gathered}
R_{i}=2 \cdot Z_{T 1} \cdot \ln \left(\frac{1}{\gamma}\right) \cdot \frac{h_{i}}{l_{1}+l_{2}+l_{3}} \quad(i=1,2,3) \\
R_{4}=2 \cdot Z_{T 2} \cdot \ln \left(\frac{1}{\gamma}\right), \quad L_{i}=2 \cdot R_{i} \cdot \tau, \quad \tau=\frac{H}{v_{T}}
\end{gathered}
$$

where: $Z_{T 1}$ and $Z_{T 2}$ are the surge impedance of the three upper tower sections, and of the tower foot section respectively, $h_{i}$ is the height of each tower section, $\gamma$ is an attenuation coefficient $(\gamma=0.8944)$ and $\tau$ is the wave travel time across the tower.

\section{Hara Multi-Story Tower Model}

Measurements on scaled and real size transmission line towers showed that the surge impedance of conductors is reduced about $10 \%$ by adding the bracings to the main legs. To take into account this reduction in the real value of tower surge impedance Hara proposed [7] a multi-story tower model (see Fig. 3) where he introduced for each tower section an additional parallel surge impedance:

$$
Z_{L k}=9 \cdot Z_{T k}, k=(1,2,3,4)
$$

where: $Z_{T}$ is the surge impedance of each tower section.

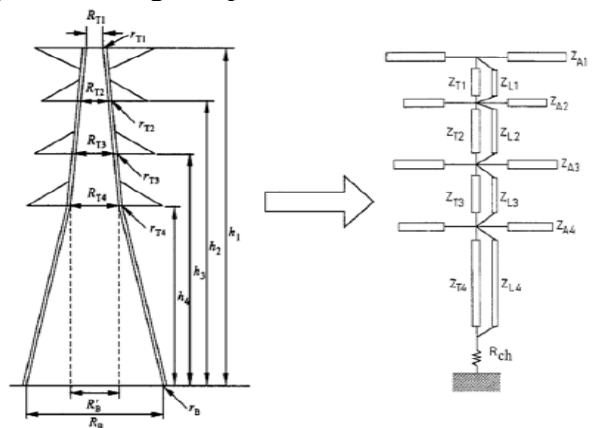

Fig. 3. Hara Multi-Story Tower Model.

Also for each tower crossarm Hara introduced an equivalent transmission line component based on the surge impedance expression for a conventional horizontal conductor: 


$$
Z_{A k}=60 \cdot \ln \frac{2 \cdot h_{k}}{r_{A k}}, \quad r_{A k}=\frac{l_{A k}}{4}
$$

where: $h_{A k}$ and $r_{A k}$ are respectively the height and the equivalent radius of the $k^{\text {th }}$ crossarm ( $1 / 4$ of the crossarm length)

\section{Proposed Multi-Story Tower Model}

In order to take into account both the presence of tower crossarms, the damping effect of each tower section and the surge impedance values reduction produced by bracings a new combined tower model has been implemented by the authors based on the previously presented two multi-story tower models, see Fig. 4.
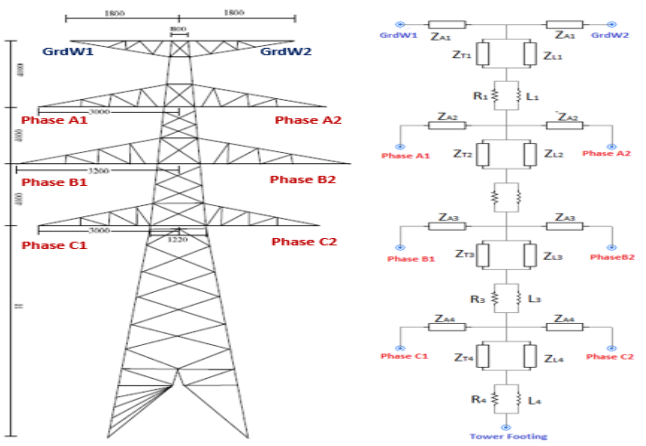

Fig. 4. Proposed Multi-Story Tower Model.

In order to eliminate unwanted wave reflections the authors propose to use the same surge impedance value considering one single section for the upper part of the tower. To obtain accurately the surge impedance of each tower section the Ametani formula, should to be used.

\section{E. Tower Footing Impedance}

In order to take into account soil ionization phenomena tower footing could be represented by a current dependent variable resistance driven by equation (5) proposed by CIGRE [2] and IEEE [5]:

$$
R_{T}=\frac{R_{0}}{\sqrt{1+\frac{I}{I_{C}}}} ; I_{C}=\frac{1}{2 \pi} \cdot \frac{E_{0} \cdot \rho}{R_{0}{ }^{2}}
$$

where: $R_{T}$ is the current dependent tower footing resistance, $R_{0}$ is the low current and low frequency footing resistance, $I_{C}$ is the limiting current to initiate soil ionization, $I$ is the strike current, $\rho$ is the soil resistivity and $E_{0}$ is the soil ionization gradient.

\section{SURGE ARRESTER MODELLING}

Laboratory test data has showed that metal oxide arresters have a dynamic discharge voltage and current characteristics that are significant for studies involving fast front surges. Therefore, several models, at different voltage levels, have been proposed in the literature to represent the frequency dependent characteristic of metal oxide surge arresters. The most commonly used models, that take into consideration both physical parameters and operating characteristics provided by manufacturers are presented below:

\section{A. IEEE Model}

The equivalent circuit model of metal oxide arresters developed by IEEE Working Group 3.4.11 [10] consists of two non-linear resistances separated by an R-L filter (see Fig. $5)$ :

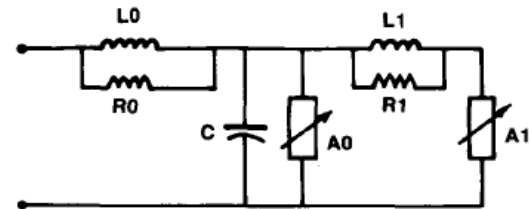

Fig. 5. The IEEE metal oxide surge arrester model [10]

The V-I characteristic of the two non-linear resistance are presented in [10] while the parameters of R-L-C elements can be evaluated based on surge arrester geometry using:

$$
\begin{gathered}
L_{0}=\frac{0.2 \cdot d}{n}[\mu H], R_{0}=\frac{100 \cdot d}{n}[\Omega], C=\frac{100 \cdot n}{d}[p F] \\
L_{1}=\frac{15 \cdot d}{n}[u H], R_{1}=\frac{65 \cdot d}{n}[\Omega]
\end{gathered}
$$

where: $d$ and $n$ are the height and number of parallel arrester columns.

\section{A. Fernandez Model}

In [11] Fernandez presents a simplified version of the IEEE model where the two parallel resistances are substituted for only one, in parallel to a capacitance, and one of the inductances is eliminated (see Fig. 6):

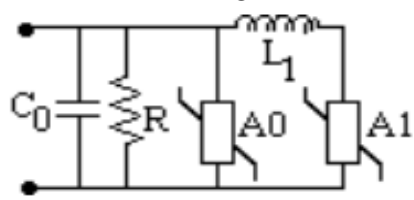

Fig. 6. The Fernandez Model [11].

The value of $R$ has to be set to $10 \mathrm{M} \Omega$ for high voltage surge arresters while $\mathrm{C}_{0}$ can be evaluated according to the IEEE model, and $L_{l}$ is the product between the number of valve blocks and inductance of a single valve block.

\section{B. Pinceti Model}

Another simplified model derived from the IEEE Model was proposed by Pinceti and Giannettoni in [12] (see Fig. 6). The capacitance is eliminated, and only electrical parameters are used. The two parallel resistances are substituted for only one, in order to avoid numerical overflow:

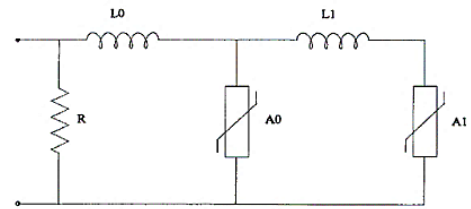

Fig. 7. The Pinceti metal oxide surge arrester model [12].

The V-I characteristic of the two non-linear components (A0 and A1) are presented in [12] while the value of L0 and L1 could be evaluated based on the discharge voltage across the surge arrester for $10 \mathrm{kA}$ lightning test current according 
to:

$$
L_{0}=\frac{1}{12} \cdot \frac{V_{1 / T}-V_{8 / 20}}{V_{8 / 20}}[\mu H], L_{1}=\frac{1}{4} \cdot \frac{V_{1 / T}-V_{8 / 20}}{V_{8 / 20}}[\mu H]
$$

The above presented surge arrester models have been implemented for a $380 \mathrm{kV}$ outdoor type surge arrester connected at the investigated GIS entrance. Simulated discharge voltages obtained after a proper tuning of surge arrester model parameters are presented in Table IV and compared to measured test values provided by manufacturer.

TABLE IV

Simulation Discharge Voltage For DifFERENT S.A. Models

\begin{tabular}{|c|c|c|c|c|c|c|c|c|c|c|}
\hline \multirow{2}{*}{\multicolumn{2}{|c|}{ Discharge Voltage }} & \multirow{2}{*}{$\begin{array}{c}12 \text { us } / 2 \text { us } \\
20 \mathrm{kA}\end{array}$} & \multicolumn{4}{|c|}{8 us / 20 us } & \multicolumn{3}{|c|}{30 us / 60 us } & \multirow{3}{*}{$\begin{array}{l}\text { Avg. } \\
\text { Err. } \\
\text { [\% }\end{array}$} \\
\hline & & & $5 \mathrm{kA}$ & $10 \mathrm{kA}$ & $20 \mathrm{kA}$ & $40 \mathrm{kA}$ & $0.5 \mathrm{kA}$ & $1 \mathrm{kA}$ & $2 \mathrm{kA}$ & \\
\hline Data Set & {$[\mathrm{kV}]$} & \begin{tabular}{|l|}
969 \\
\end{tabular} & 801 & 842 & 918 & 1003 & 691 & 718 & 741 & \\
\hline \multirow{2}{*}{ IEEE Model } & {$[\mathrm{kV}]$} & 974.92 & 806.49 & 854.95 & 921.47 & 1004.02 & 677.78 & 716.3 & 754.19 & \multirow{2}{*}{$0.905 \%$} \\
\hline & [\%] & $0.611 \%$ & $0.685 \%$ & $1.538 \%$ & $0.378 \%$ & $0.102 \%$ & $1.913 \%$ & $0.237 \%$ & $1.780 \%$ & \\
\hline \multirow{2}{*}{ Pinceti } & [kV] & 971.89 & 801.43 & 852.8 & 918.12 & 1008.76 & 692.23 & 727 & 752.07 & \multirow{2}{*}{$0.643 \%$} \\
\hline & [\%] & $0.298 \%$ & $0.054 \%$ & $1.283 \%$ & $0.013 \%$ & $0.574 \%$ & $0.178 \%$ & $1.253 \%$ & $1.494 \%$ & \\
\hline \multirow{2}{*}{ Fernandes } & [kV] & 969.92 & 821.79 & 845.42 & 924.29 & 1016.27 & 677.99 & 802.63 & 807.11 & \multirow{2}{*}{$3.462 \%$} \\
\hline & [\%] & $0.095 \%$ & $2.596 \%$ & $0.406 \%$ & $0.685 \%$ & $1.323 \%$ & $1.883 \%$ & $11.787 \%$ & $8.922 \%$ & \\
\hline
\end{tabular}

\section{LIGHTNING CURRENT MODELLING}

The lightning current produced by a lightning stroke to an overhead transmission line could be model using a variable current source in parallel with a $400 \Omega$ resistance representing the air path between the clouds and the transmission line. To describe the lightning impulse current usually manufactures use a Ramp, eq. (9), or a Double Exponential, eq. (10), function which are easier to implement in test equipment.

$$
\begin{gathered}
I_{\text {Ramp }}(t)=\left\{\begin{array}{cc}
\frac{I_{L C}}{t_{f}} \cdot t & t \leq t_{f} \\
\frac{I_{L C}}{2 \cdot\left(t_{h}-t_{f}\right)} \cdot\left(2 t_{h}-t_{f}-t\right) & t>t_{f}
\end{array},\right. \\
I_{D E x p}(t)=I_{L C} \cdot\left(e^{-A \cdot t}-e^{-B \cdot t}\right)
\end{gathered}
$$

where: $I_{L C}$ is the amplitude of the lightning current, $t_{f}$ is the time to front, $t_{h}$ is the time to half, while $A$ and $B$ are exponential coefficients for the double exponential model.

In 1991 based on statistical analysis of recorder lightning strikes around the world CIGRE [2] proposed a more complex formulation of lightning current which to take into account the concave form of the rise up part:

$$
I_{\text {CIGRE }}(t)=\left\{\begin{array}{cc}
A_{1} \cdot t+A_{2} \cdot t^{n} & t \leq t_{c} \\
B_{1} \cdot \exp \left(-\frac{t-t_{c}}{t_{1}}\right)-B_{2} \cdot \exp \left(-\frac{t-t_{c}}{t_{2}}\right) & t>t_{c}
\end{array}\right.
$$

where: $t_{c}$ is the time to crest, $t_{l}$ and $t_{2}$ are time parameters and A1, A2, B1, B2 are coefficient parameters which describe the front and the tail part of lightning current waveform [2].

Recently in literature the Heilder lightning current function [13] is used for the study of fast front overvoltages produced by lightning strikes to overhead power lines:

$$
I_{\text {Heidler }}(t)=\frac{I_{L C}}{\eta} \cdot \frac{\left(\frac{t}{t_{f}}\right)^{n}}{1+\left(\frac{t}{t_{f}}\right)^{n}} \cdot \exp \left(-\frac{t}{t_{h}}\right)
$$

where: $n$ is the order of the implemented Heidler function and $\eta$ is a scaling coefficient.

\section{CASE Study}

In order to determine the effect of the different simulation component models presented above on the produced FFO values at GIS entrance in case of a lightning strike to an adjacent power line the situation of a $380 \mathrm{kV}$ double circuit transmission line connected to a one and half bus configuration $420 \mathrm{kV}$ GIS is investigated (see Fig. 8). The $380 \mathrm{kV}$ overhead power line consist in 2 ground wires and 6 phase wires placed in an anti-symmetrical phase arrangement on S1N type power line towers. Table $\mathrm{V}$ presents the geometry of the power line tower, while in Table VI the position of each transmission line conductor on the tower is presented.

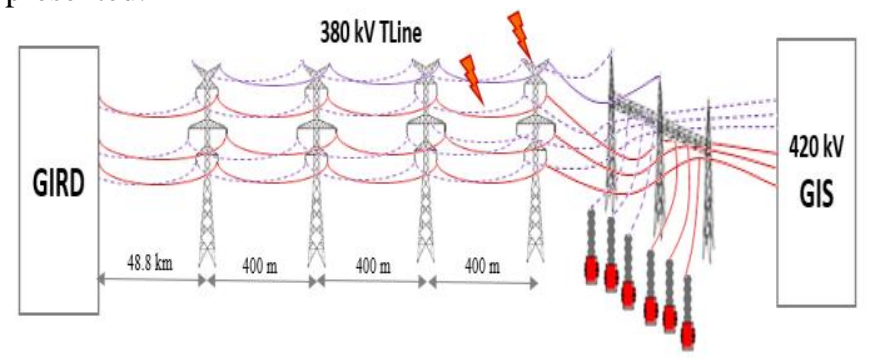

Fig. 8. Investigate $380 \mathrm{kV}$ overhead power line.

TABLE V

POWER LINE TOWER STRUCTURE GEOMETRY

\begin{tabular}{|c|c|c|c|c|c|c|c|}
\hline \multicolumn{2}{|c|}{ Section Width } & \multicolumn{2}{c|}{ Conductor Radius } & \multicolumn{2}{c|}{ Section Height } \\
\hline $\begin{array}{c}\mathbf{D}_{\mathrm{T}} \\
{[\mathbf{m}]}\end{array}$ & $\begin{array}{c}\mathbf{D}_{\mathbf{M}} \\
{[\mathbf{m}]}\end{array}$ & $\begin{array}{c}\mathbf{D}_{\mathrm{B}} \\
{[\mathbf{m}]}\end{array}$ & $\begin{array}{c}\mathbf{r}_{\mathrm{T}} \\
{[\mathbf{m m}]}\end{array}$ & $\begin{array}{c}\mathbf{r}_{\mathrm{M}} \\
{[\mathbf{m m}]}\end{array}$ & $\begin{array}{c}\mathbf{r}_{\mathrm{B}} \\
{[\mathbf{m m}]}\end{array}$ & $\begin{array}{c}\mathbf{H}_{1} \\
{[\mathbf{m}]}\end{array}$ & $\begin{array}{c}\mathbf{H}_{\mathbf{2}} \\
{[\mathbf{m}]}\end{array}$ \\
\hline 1.9 & 2.09 & 2.5 & 80 & 124 & 152 & 30 & 27 \\
\hline
\end{tabular}

TABLE VI

CONDUCTORS POSITION ON TOWER

\begin{tabular}{|l|c|c|l|c|c|}
\hline \multicolumn{1}{|c|}{ Conductor } & Position [m] & Height [m] & Conductor & Position [m] & Height [m] \\
\hline Phase Wire A1 & -12.232 & 52 & Phase Wire A2 & 12.232 & 30 \\
\hline Phase Wire B1 & -12.232 & 41 & Phase Wire B2 & 12.232 & 41 \\
\hline Phase Wire C1 & -12.232 & 30 & Phase Wire C2 & 12.232 & 52 \\
\hline Ground Wire 01 & -5.2 & 57 & Ground Wire 02 & 5.2 & 57 \\
\hline
\end{tabular}

Both back flashover and direct lightning strike situations are analysed considering that lightning strike hits in the vicinity of the first tower from the GIS entrance (see Fig. 8). Obtained overvoltage values and waveform using different simulation component models are compared to each other and to the basic insulation level of the GIS (BIL $=1425 \mathrm{kV})$.

\section{Simulation Results}

\section{Back Flashover Study}

Due the fact that the insulator string may withstand a high transient voltage for a short duration, but it could fail to withstand a lower transient voltage with a longer duration, the volt-time characteristic proposed by CIGRE [2] has been implemented for the back flashover simulations.

To identify the effect of using different tower models in the simulations of a back flashover on the $380 \mathrm{kV}$ power line, the first five tower from the GIS entrance are model using the proposed tower model. Obtained FFO values and waveforms 
are compared with the situation when the towers were modeled using the single and multi-story transmission line models presented in section II: the simple multi-story model, the Ishii and respectively Hara multi-story model. Fig. 9 presents the evaluated FFO at GIS entrance for each implemented tower model in case of $225 \mathrm{kA}, 1.2 / 50 \mu \mathrm{s}$ lightning current considering that no surge arrester are connected to the GIS and the back flashover appears on the left side upper conductor (A1) when the phase voltage riches its negative peak value.

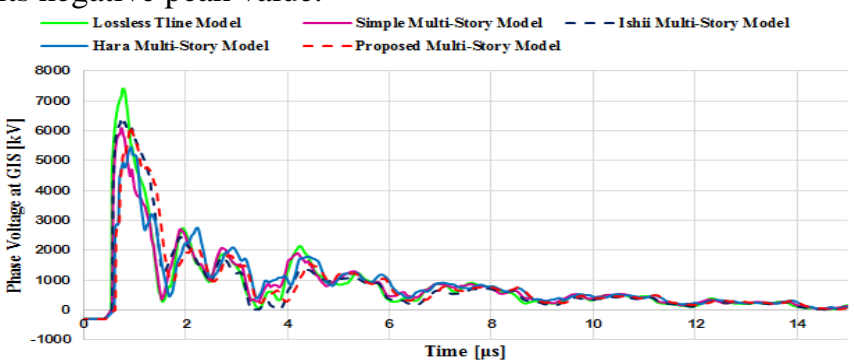

Fig. 9. Produced back flashover FFO at GIS entrance considering different tower models and no surge arresters connected.

From Fig. 9 it can be observed that by neglecting the different overvoltage levels produced at tower crossarms the single TLine model provides an overestimation of the produced FFO at GIS entrance. On the other hand, by taking into consideration the presence of tower crossarms and bracings the Hara multi-story model introduces more oscillations in the produced FFO waveform, due to inside tower wave reflections. The proposed tower model makes o good correlation between the evaluated overvoltage levels and the introduced oscillations by crossarm reflections. Compared to the Ishii and the simple multi-story models, the proposed tower model presents a small delay when the FFO waveform riches its peak values. All the implemented tower model produce overvoltage levels much higher than the GIS basic insulation level.

However, if surge arresters are connected at GIS entrance no significant difference (less than $1 \%$ ) could be observed between the FFO waveforms produced by the different tower models. In this case the FFO seen by the GIS are limited to around $1050 \mathrm{kV}$ (under GIS BIL = $1425 \mathrm{kV}$ ). Fig. 10 presents the obtained FFO waveforms at GIS entrance using the proposed tower model and considering each of the surge arrester models presented and implemented in section III of this paper:

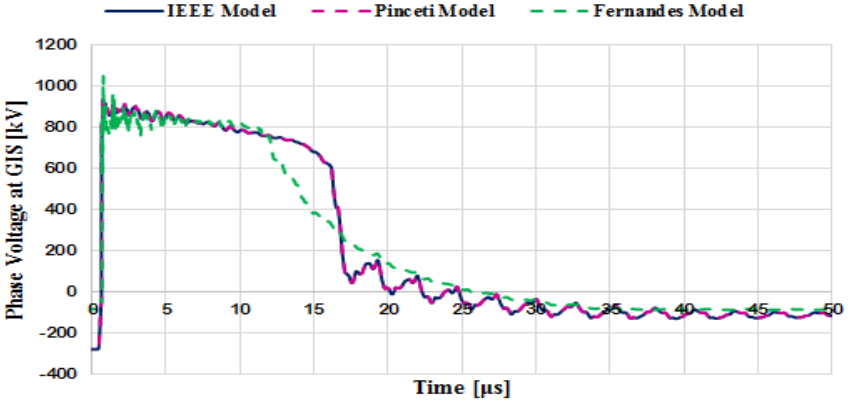

Fig. 10. Produced back flashover FFO at GIS entrance for different surge arrester model implementations.
It can be observed that the IEEE and Pinceti surge arrester models provides similar results while the Fernandez model produces more oscillations at the beginning of the FFO waveform.

To show the effect of different tower footing impedance values the produced FFO waveform at GIS entrance have been evaluated considering $20 \Omega, 10 \Omega, 5 \Omega$ and respectively the CIGRE soil ionization model, for the footing impedance of the first tower while the footing resistance of all the other towers has been set to $20 \Omega$. Obtained simulation results are presented in Fig. 11. It can be observed the each case approximately the same maximum overvoltage level is obtained, however the attenuation of the produced FFO waveform depends very much on the implemented footing resistance. The CIGRE proposed soil ionization model provides the fastest FFO waveform attenuation (see Fig. 11).

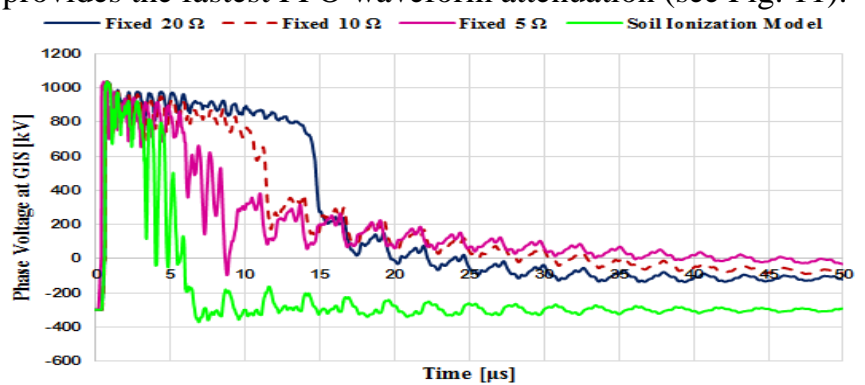

Fig. 11. Produced back flashover FFO at GIS entrance for tower footing impedance values.

Finally the influence of different lightning current models (different mathematical function implementation) has been investigated. Obtained results considering a $225 \mathrm{kA}, 1.2 / 50$ $\mu$ s lightning current waveform, Pinceti type surge arrester models connected to GIS entrance, and the proposed tower model with fixed $20 \Omega$ footing resistance are presented in Fig. 12:

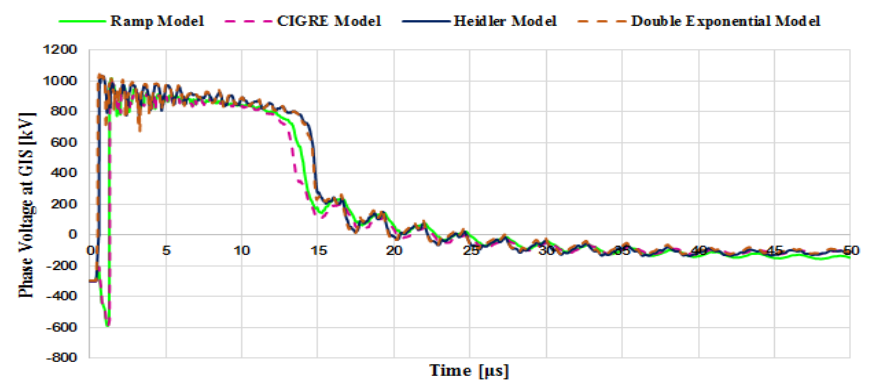

Fig. 12. Produced black flash FFO at GIS entrance for different lightning current functions.

Due their exponential rise up curve the double exponential and the Heidler function implementations provide an earlier and a higher overvoltage peak value while in case of the ramp and the CIGRE models a first negative overvoltage peak can be observed.

\section{Direct Strike Study}

Direct lightning due to shielding failure could occur on the upper or the most outward phase wire. The maximum intensity of a lightning strike that could produce shielding failure can be evaluated based on tower geometry, striking distance and the implemented lightning attachment model 
[14].

Therefore,

a $20 \mathrm{kA} 1.2 / 50 \mu \mathrm{s}$ lightning current waveform has been selected for the direct strike study.

Analyzing the produced FFO waveforms at GIS entrance it has been concluded by the authors that the implemented power line tower, and footing impedance models have no direct effect on the obtained simulation results. Fig. 13 presents the obtained direct strike FFO waveforms at GIS entrance for different implemented tower models with no surge arresters connected to GIS. In this case the evaluated maximum overvoltage level is almost double than the basic insulation level of the GIS $(\mathrm{BIL}=1425 \mathrm{kV})$.

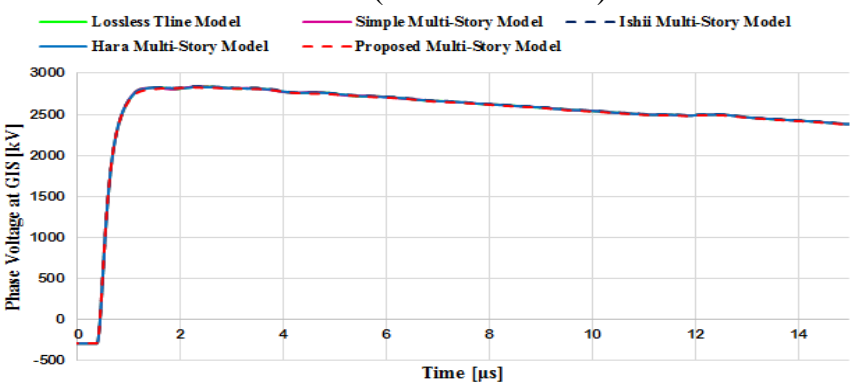

Fig. 13. Produced direct strike FFO at GIS entrance considering different tower models and no surge arresters connected.

Fig. 14 presents the evaluated FFO waveforms at GIS entrance considering the implementation of different surge arrester equivalent circuit models. It can be observed that due the presence of surge arresters at GIS gantry tower site the overvoltage level seen by the GIS is limited to approximately $800 \mathrm{kV}$ for the $20 \mathrm{kA}, 1.2 / 50 \mu$ s lightning strike. The IEEE and Pinceti surge arrester models provides similar results while Fernandez's model produces a faster decay on the FFO waveform seen by the GIS.

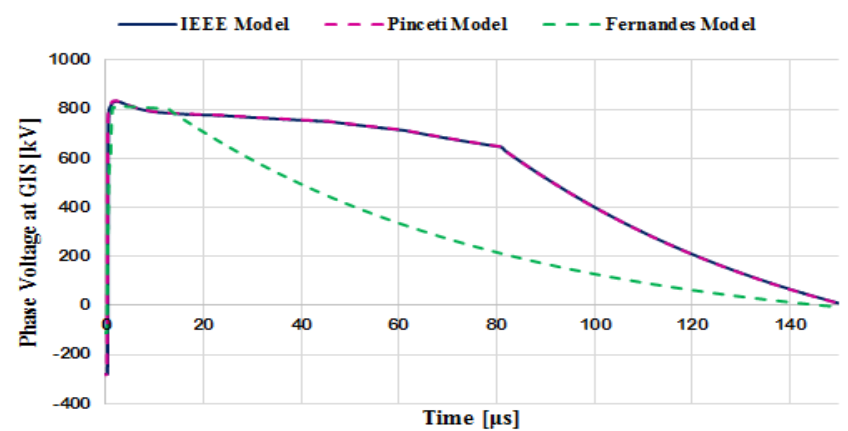

Fig. 14. Produced direct strike FFO at GIS entrance for different surge arrester model implementations.

Finally the influence of different lightning current function implementation in case of a direct strike has been investigated, considering a $20 \mathrm{kA}, 1.2 / 50 \mu$ s lightning current waveform.

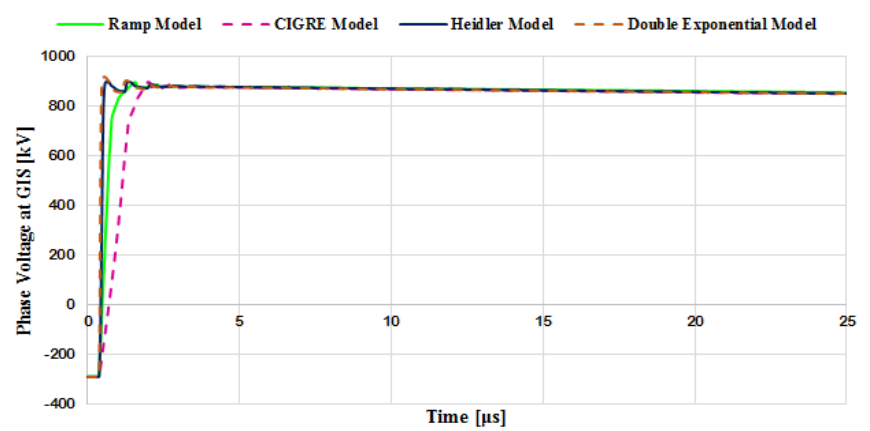

Fig. 15. Produced direct strike FFO at GIS entrance for different lightning current functions.

Obtained results (see Error! Reference source not found.) showed that the four different lighting current function implementation produce similar FFO waveforms only the overvoltage rise up front differs from one implementation to the other. The double exponential and the Heidler function provide the fastest FFO rise up fronts.

\section{CONCLUSIONS}

The influents of different simulation component models (like transmission line towers, footing impedance, surge arresters or lightning current) on fast front transient overvoltage evaluation in case of lighting strokes to overhead power lines connected to GIS has been investigated.

A new more realistic transmission line tower model that makes o good correlation between the evaluated overvoltage levels and the produced oscillations by crossarm reflections, has been proposed by the authors. Obtained FFO waveforms have been compared to other existing tower models.

The investigation of different equivalent circuit models in case metal oxide surge arresters has concluded that the IEEE and the Pinceti models provide similar results while the Fernandez models produces more oscillations at the beginning of the FFO waveform and a faster decay, which could provide a significant difference in the evaluation of the discharged energy levels during a lightning strike.

\section{ACKNOWLEDGEMENTS}

The paper has been financially supported by Hyundai Heavy Industries Co., Ltd. Dong-gu Ulsan, South Korea.

\section{REFERENCES}

[1] IEEE Fast Front Transients Task Force, "Modeling Guidelines for Fast Front Transients", IEEE Trans. on Power Delivery, vol. 11, no. 1, pp. 493-506, January, 1996.

[2] CIGRE, Guide to Procedures for Estimating the Lightning Performance of Transmission Lines, CIGRE Technical Report 063, October, 1991.

[3] IEC 60071-4, "Insulation Coordination - Part 4: Computational Guide to Insulation Coordination and Modelling of Electrical Networks", International Electrotechnical Commission, (IEC), p. 122, June, 2004.

[4] J.A. Martinez-Velasco, Power Systems Transients. Parameter Determination, Boca Raton: CRC Pres, 2010.

[5] IEEE Working Group, "Estimating Lightning Performance of Transmission Lines. II. Updates to Analytical Models", IEEE Trans. on Power Delivery, vol. 8, no. 3, pp. 1254-1267, 1993.

[6] A. Ametani, Y. Kasai, J. Sawada, A. Mochizuki, and T. Yamada, "Frequency-Dependent Impedance of Vertical Conductors and A Multiconductor Tower Model", IEE Proceedings - Generation, 
Transmission and Distribution, vol. 141, no. 4, pp. 339 -345, July, 1994.

[7] T. Hara, and O. Yamamoto, "Modelling of a Transmission Tower for Lightning Surge Analysis", IEE Proceedings - Generation, Transmission and Distribution, vol. 143, no. 3, pp. 283 - 289, May, 1996.

[8] Y. Baba, and M. Ishii, "Numerical Electromagnetic Field Analysis on Measuring Methods of Tower Surge Impedance", IEEE Trans. on Power Delivery, vol. 14, no. 2, pp. 630 - 635, April, 1999.

[9] A. Ametani, and T. Kawamura, "A Method of a Lightning Surge Analysis Recommended in Japan Using EMTP," IEEE Trans. on Power Delivery, vol. 20, no. 2, pp. 867 - 895, April, 2005.

[10] IEEE Working Groop, "Modeling of Metal Oxide Surge Arresters," IEEE Trans. on Power Delivery, vol. 7, no. 1, pp. 302-309, January, 1992.
[11] F. Fernández, and R. Diaz, "Metal-Oxide Surge Arrester Model for Fast Transient Simulations ", International Conference on Power System Transients, (IPST), Rio de Janeiro, Brasil, 24-28 June, 2001.

[12] P. Pinceti, and M. Giannettoni, "A Simplified Model for Zinc Oxide Surge Arresters," IEEE Trans. on Power Delivery, vol. 14, no. 2, pp. 393-398, April, 1999.

[13] A. Ceclan, V. Topa, D. D. Micu, and A. Andreotti, "Lightning-Inverse Reconstruction by Remote Sensing and Numerical-Field Synthesis," IEEE Trans. on Magnetics, vol. 49, no. 5, pp. 1657 - 1660, May, 2013.

[14] P. N. Mikropoulos, and T. E. Tsovilis, "Lightning Attachment Models and Maximum Shielding Failure Current of Overhead Transmission Lines: Implications in Insulation Coordination of Substations," IET Generation, Transmission \& Distribution vol. 4, no. 12, pp. 1299 1313, December, 2010. 